\title{
Prospects for Sperm Immunocontraceptive Vaccines
}

\author{
Pius A. Adoyo ${ }^{1,2)}$ and Koji Koyama ${ }^{2)}$ \\ ${ }^{1)}$ Division of Reproductive Biology, Institute of Primate Research, National Museums of Kenya, \\ P.O. Box 24481, 00502 Karen, NAIROBI, KENYA \\ ${ }^{2)}$ Department of Obstetrics and Gynecology, Hyogo College of Medicine, \\ 1-1 Mukogawa-Cho, Nishinomiya 663-8501, JAPAN
}

\begin{abstract}
The global population growth rate represents one of the greatest threats to mankind to day. Most of today's population is concentrated in the developing countries and if left unchecked, may lead to deleterious consequences. Contraception is one of the ways of controlling population growth, however, contraceptive methods used today are not available to many individuals due to sociological, financial, or educational limitations. Immunocontraception may provide alternative to the current contraceptive methods due to its reversibility and the fact that most of the developing countries where population growth is highest, have service infrastructure for delivery of disease vaccines into which contraceptive vaccines could be incorporated. Immunizations against sperm components are feasible since antibodies can be raised against unique antigens on spermatozoa and interfere with fertilization process. However, whole sperm cannot be used for immunization as it shares some somatic epitopes that may have harmful effects. Therefore, a unique sperm specific and acceptable immunogen must be found which has no harmful effects. A number of sperm specific proteins with immunocontraceptive potential have been identified, however only a small number (Sp-10, Sp-17, FA-1, PH-20 and LDH-C4) have been extensively characterized. This article evaluates the current status of these and other sperm targeted molecules that have been proposed as candidates for immunocontraceptive vaccine. Choice of non-human primate animal models for contraceptive vaccine development is also highlighted. It further discusses the problems encountered in the development of these molecules to full contraceptive agents.
\end{abstract}

Key Words: Spermatozoa, Sperm antigens, Immunocontraception, Vaccines

\section{Introduction}

\section{Population growth and its effects}

In 1850 , the world population was 1 billion. It doubled in eighty years from 1850, in 1930. It tripled, reaching 6 billion in October $1999[1,2]$. If the present demographic statistics persist; it is estimated that the global population will be 19 billion in the year 2100 and the eventual population will be 28 billion by 2150 . Ninety-five percent of this global population growth is concentrated in the developing countries [2]; as a result $80 \%$ of the total world population will be concentrated in the developing countries. This will give rise to pollution, environmental degradation, and further pressure on already scarce resources such as health and service provision with a subsequent lowering of the standard and quality of living in these countries. Thus the development of new methods of immunocontraception cannot be underscored, and especially when the global abortion rates are considered [4]. Thirty eight 
percent of the estimated 210 million pregnancies occurring worldwide each year are unintentional and $22 \%$ (46 million) end up in abortion [4]. It has further been found that maternal mortality correlate with economic status. A woman receiving an abortion in Africa is 7000 times more likely to die of complications than her counterpart in Canada (680 per 100,000 compared with 0.1 per 100,000 ). The high rate of unplanned pregnancy and abortion worldwide is attributed to inadequate availability and use of contraceptives. In the light of this global population explosion, unintended pregnancies and abortion rates, continued search for safe, acceptable and reliable means of fertility regulation is an absolute necessity and needs of developing countries must be put into consideration.

\section{Reproduction and Immunocontraception}

A number of contraceptive methods are currently available, however, most of them have various limitations including, undesirable side effects, un-sustainability, unavailability for a proportion of the population due to cultural, economic or personal reasons, or not providing adequate protection against pregnancy [5]. One of the possible methods of contraception that is receiving increased attention is immunocontraception. This makes use of the body's immune system to block an indispensable step in process of gamete interaction during fertilization. Events in the fertilization sequence, including sperm capacitation, sperm-cumulus interaction, sperm-zona binding, the acrosome reaction, zona penetration and gamete fusion, represent potential targets for immunological interference [6]. The feasibility of this approach is clearly evidenced by the relatively large numbers of otherwise healthy men and women whose infertility is associated with the presence of anti-sperm antibodies [7]. Furthermore, experimental data exists dating back to the 1930s suggesting that should be possible to induce a state of active immunity against antigens in human semen [8]. This review article is to evaluate the current status of sperm antigens that have been identified, characterized and proposed as potential candidates for immunocontraception, and to discuss their relative merits in the development of a contraceptive vaccine.

\section{Attributes of an ideal Immunocontraceptive}

The suitability of an antigen for use in human immunocontraception is determined by its tissue specificity, involvement in human fertility and immunogenicity. A good contraceptive vaccine would therefore have to be safe, reliable, affordable, easy to administer and capable of evoking a homologous response in most or all individuals and also acceptable to a wide range of the population. If antigens targeted for contraceptive purposes are carefully selected, then such vaccines would also be free from harmful side effects since they are able to target gene products that are unique to the reproductive system. Further, it should have a long lasting but reversible contraceptive effect that can be assessed by simple assays [5]. The last attribute, prolonged protection should be a feature of all vaccines that provoke active immunity against key antigens. Despite the existence of great amount of information for the development of an immunocontraceptive, major problem facing researchers seeking to induce any active immunity against reproductive antigens today are reliability, reversibility [ 4 for review], safety and immunogenicity.

\section{Sperm antigens with immunocontraceptive potential}

A large number of sperm candidate-binding partners for the ZP proteins have been identified and described; various groups have been characterized structurally and functionally. Most have been identified screening using polyclonal and monoclonal antibodies generated following immunization of rodents with whole sperm or purified sperm components. Only a small number of these molecules have been documented and shown to be involved in sperm-zona recognition include: - Sp-10, Sp-17, FA-1, PH-20 and LDH-C4 (Table 1). Other reported antigens requiring 
further investigations include: - the mouse NZ-1 and NZ-2, YLP (12), Sperm agglutination antigen1 (SAGA-1), and the testis/sperm-specific contraceptive vaccinogen (CV). Fertilins- $\alpha$ and $-\beta$, and the cyritestin [or tMDC 1], belong to a rapidly growing family of integral membrane proteins, all of which contain a number of distinct conserved features including a metalloproteinase-like domain, a disintegrin-like domain, a cystein-rich domain, a pro-domain and a trans-membrane domain. They are also known as the ADAM family; proteins with A Disintegrin and Metalloproteinase domain. A number of ADAM family proteins are expressed within the mammalian testis with an increasing number detected on spermatogenic cells, hence having a role in reproductive function. This family of proteins are discussed elsewhere [5].

\section{$S p-10$}

$\mathrm{Sp}-10$ is a sperm protein that was identified using the MHS-10 monoclonal antibody. The MHS-10 monoclonal antibody interferes with Sperm Penetration Assay (SPA) by causing sperm agglutination. The $\mathrm{Sp}-10$, antigen is an intraacrosomal protein and has been isolated and characterized from spermatozoa in human and many other mammalian species including mouse, fox, bovine, porcine and from non-human primates such as baboons and the rhesus monkeys $[9,10]$. Using multiple tissue northern blots on mRNA from 36 tissues in female baboons and southern blots of $\mathrm{Sp}-10 \mathrm{PCR}$ products, it was concluded that $\mathrm{Sp}-10$ is exclusively expressed in the testis and that its gene products are testis specific; characteristics essential for contraceptive candidate molecule [11]. The human and baboon cDNA have been cloned and sequenced and recombinant proteins produced in E. coli [12]. Two alternatively spliced Sp-10 cDNAs were obtained from both baboon and macaque testis libraries. The two cDNAs in each species contained open reading frames (ORF's) encoding proteins of exactly 285 and 251 amino acids (aa). A 98\% homology between baboon and macaque $\mathrm{Sp}-10$ was found at the protein and DNA levels. An $85 \%$ and $89 \%$ homology between baboon and macaque Sp-10 and human $\mathrm{Sp}-10$ was present at the protein and DNA level, respectively. A mouse intra-acrosomal protein, MSA-63, considered to be an Sp-10 homologue, exhibited an overall $53 \%$ homology to non-human primate Sp-10 and a $60 \%$ homology to human $\mathrm{Sp}-10$ at the protein level. The comparisons of human, baboon, and macaque Sp-10 cDNA sequences indicated that the baboon and macaque cDNAs contained 60 bp (20 aa) not present in the human Sp-10 cDNA. Analysis of the human $\mathrm{Sp}-10$ genomic sequence suggests that a 60-bp deletion may have occurred during the evolution of the human Sp-10 gene by homologous recombination [13]. Immunization of female baboons with recombinant proteins to the full length human (re-hSp-10) and baboon (rebSp-10) sequence produced antibodies that reacted with native $S p-10$ extracted from human sperm in a manner identical to that of MHS-10, the positive control. Immune sera also stained the acrosomal region of human and baboon sperm by immunofluorescence [12]. Systemic immunizations of macaques with homologous recombinant proteins produced elevated levels of oviductal IgAs and serum $\mathrm{lgGs}$ at cycle 2 and all subsequent intervals. Reddy and co-workers generated serum antibodies to the recombinant $\mathrm{Sp}-10$ that recognized $\mathrm{Sp}-10$ extracted from macaque sperm on Western blots. Immunocytochemical staining of macaque and human sperm showed acrosomal immunofluorescence with both immune oviductal fluids and serum using both anti-lgG and anti-lgA secondary antibodies [14]. Although the molecular characterization of the $\mathrm{Sp}-10$ protein has been clarified, the functional role of this protein with regard to fertilization is yet to be known. In the bovine, fertilization experiments in vitro demonstrated that monoclonal antibodies, as well as polyclonal antibodies, to human Sp-10 significantly reduced fertilization rates of bovine oocytes by bovine spermatozoa. These antibodies further reduced the ability of capacitated spermatozoa to complete the acrosome reaction as well as affected the motility of capacitated spermatozoa, but not that of the non-capacitated spermatozoa [10]. Recently, a monoclonal antibody (mAb pep- 


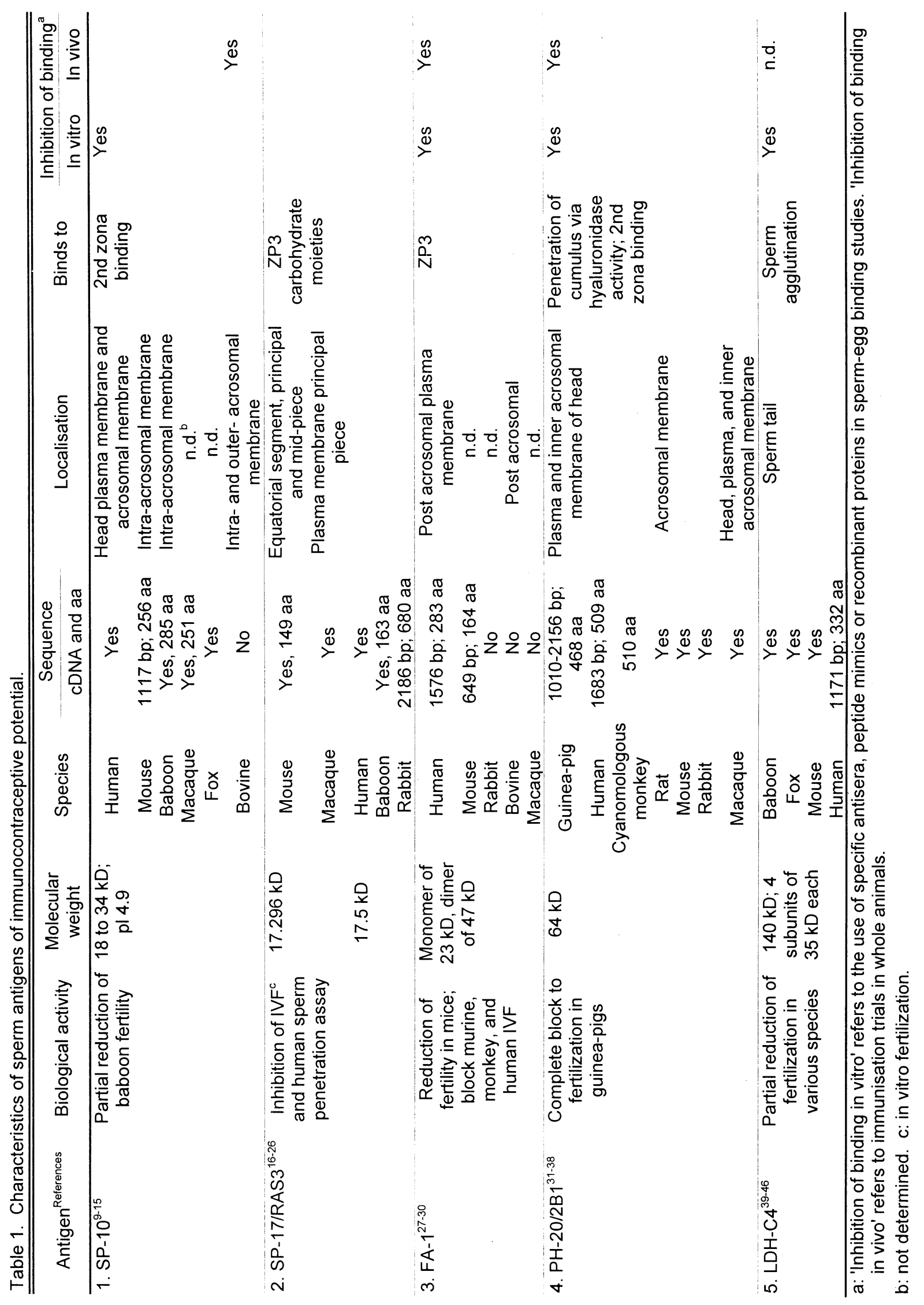


$\mathrm{Sp}-10)$ to $\mathrm{Sp}-10$ peptide that included the most hydrophilic portion of human sequence inhibited sperm-oolemma binding in the zona-free hamster egg penetration test, but it did not inhibit spermzona binding in the hemi-zona assay [15]. The data suggest that human $\mathrm{Sp}-10$, indeed mediates sperm-oolemma binding in an $\alpha-1$ integrinindependent manner, but not sperm-zona binding. However, a species-specific immunization with Sp-10 proteins needs to be done to assess its contraceptive efficacy and the induced immune response. Furthermore, due to its intraacrosomal location, it may not be possible to exploit this antigen for immunocontraceptive purposes.

\section{$S p-17$}

This is the $17 \mathrm{kDa}$ member of the rabbit sperm auto antigens (RSAs). Initially identified in rabbits, and later found to be present on sperm and spermatogenic cells of mouse, baboon and humans $[16,17,18]$. The mRNA sequence encoding a mammalian testis and sperm specific protein of $16,891 \mathrm{Da}$, (designated $\mathrm{Sp}-17$ ) has been cloned and sequenced in rabbit, mouse, humans and baboons. In rabbits, Sp-17 protein is coded by two mRNA transcripts of 0.9 and $1.1 \mathrm{~kb}$ which area similar in their coding region but only differ in their 5' UTR. Northern blot analysis revealed that mRNA to Sp-17 is present in rabbit, mouse and human testis but absent from the somatic tissues tested [19]. In the mouse, the mRNA of Sp-17 codes for 147 aa's with a predicted molecular weight of $17,296 \mathrm{Da}$. The mouse sequence was found to have $82 \%$ and $74 \%$ homology at DNA and protein levels to that of rabbit. Localization studies revealed that the mouse $\mathrm{Sp}-17$ is not available to bind antibody on the surface of live, acrosome-intact spermatozoa, but it is present on the equatorial surface of live, acrosome-reacted spermatozoa. In fixed spermatozoa, staining is observed along the length of the principal piece, weakly along the mid-piece, and over the acrosomal region of the head [18]. It can be concluded from these studies that sperm Sp-17 is intra-acrosomal and very little is present on the surface of principal piece. In the human, the Sp17 protein is coded by two mRNA transcripts of 1.3 and $1.6 \mathrm{~kb}$ with similarities and differences as those in rabbits. The predicted aa sequence revealed it to be a protein of $17.5 \mathrm{kDa}$, having high degree of homology to that of rabbit and mouse [20]. In the baboon (Papio papio) bSp-17 was found to be encoded by two mRNA transcripts of 0.8-1.35 kb. Three clones, identified were similar in their open reading frame (ORF) encoding 163 aa's with a predicted molecular weight of $18.8 \mathrm{kDa}$, but differ in their 3' UTRs. The bSp-17 was found to be specific to the baboon testes and was not detected in the ovary, placenta, or any of the other somatic tissues tested [21]. Immunization of female cyanomologous macaques with the human sperm protein $\mathrm{Sp}-17$ and synthetic peptides derived from Sp-17 resulted in the production of both oviductal and serum antibody titers. The latter varied over time for individual monkeys and between different monkeys. However, the antibody response was restricted solely to the immunoglobulin $G$ class [22]. In mice, immunization with a chimeric synthetic Sp-17 peptide (comprising a dominant B-cell epitope coupled to a common promiscuous T-cell epitope) resulted in a dose depended reduction in fertility that was strain specific and not correlated with serum or antibody levels [23]. To understand the mechanism behind this apparent strain-specific infertility induction, a more extended study on both the humoral and the cellular immune response to the chimeric peptide was performed. The antigen-specific T-cell response and the levels of antigen-specific cytokines are the major factors that affect fertility outcome. Although Sp-17 protein was originally thought to be exclusively expressed in the testis hence its primary function was to bind to the extra cellular matrix of the oocyte, emerging information have implicated Sp17 to have role in cell-cell adhesion and/or cell migration in transformed, lymphocytic and haematopoietic cells [24]. Sp-17 gene consists of three domains namely: - the $\mathrm{N}$-terminal, Central and C-terminal domains. Sp-17's central domain, which is necessary for heparin binding, exhibits the 
greatest sequence divergence of all three domains [25]. The Sp-17 gene is induced in metastatic cells and during mucosal immune responses, and the protein appears to play an important role in cell migration and/or adhesion in somatic cells, as well as in male germ cells. More recent report indicates that the sperm protein 17 (Sp-17) has also been identified as a novel cancer-testis (CT) antigen in multiple myeloma (MM). Since this tumor antigen demonstrates a very restricted normal tissue expression, $\mathrm{Sp}-17$ is also suggested to be an excellent target for tumor vaccine of MM [26]. On the basis of the extremely high sequence conservation throughout the $\mathrm{N}$-terminal half of $\mathrm{Sp}-17$, and the presence within this region of an A-kinase anchoring protein (AKAP)-binding motif, it is postulated that the proposed role of $\mathrm{Sp}$ 17 in zona pellucida binding is unlikely to be its principal function [24].

\section{Fertilization Antigen-1 (FA-1)}

The FA-1 antigen, is dimeric a glycoprotein of 23- and approximately $47 \mathrm{kDa}$ monomeric and dimeric forms respectively which was isolated using monoclonal antibody 2B1. It has been isolated from human and murine testis using a germ-cell specific, but species-cross reactive, monoclonal antibody (FA-1 mAb). The FA-1 mAb had been found to inhibit fertilization in mice and humans [27]. FA-1 is testes specific and cDNAs encoding murine and human antigen have been cloned and sequenced. In both mice and humans, the FA- 1 antigen is coded by a novel gene, and found to be unique at nucleotide/amino acid levels. The Northern blot and reverse transcription-polymerase chain reaction (RTPCR)-Southern blot analyses indicated its testisspecific expression at the mRNA level. The mouse gene has $649 \mathrm{bp}$ and 164 aa with a calculated molecular weight of $18.2 \mathrm{kDa}$. It has one potential $\mathrm{N}$-linked and at least two O-linked glycosylation sites. The FA-1 cDNA was subcloned and mouse recombinant proteins (rmFA-1) produced in a bacterial system. The latter reacted specifically with ZP3 of oocyte and affinity purified antibody completely blocked sperm-zona pellucida interaction in mice [27]. In the human, the full length FA-1 antigen gene comprise of $1,576 \mathrm{bp}$ (from RT-PCR), with an ORF of 283 aa and a calculated molecular weight of $32.1 \mathrm{kDa}$. It also has one potential $\mathrm{N}$-linked and several O-linked glycosylation sites besides one tyrosine phosphorylation, a serine and threonine phosphorylation sites. The human FA-1 cDNA was sub cloned and recombinant proteins (rhFA-1) expressed. Rabbit antibodies to rhFA-1 proteins recognized rhFA-1 as well as native FA-1 (nFA-1) antigen. These anti-rhFA-1 antibodies showed binding to specific regions on live and methanolfixed human sperm and caused a significant and concentration-dependent inhibition of human sperm capacitation / acrosome reaction by blocking tyrosine phosphorylation of the FA-1 antigen [28]. Active immunizations with rmFA-1, raised high antibody titers in all the 16 mice (two trials) and the antibody levels lasted longer (255 days), before reverting to the pre-immune levels. There was significant reduction in fertility of the immunized animals and that the immunized animals delivered healthy babies without effect on litter size, when antibody levels declined to those of control, indicating that rmFA-1 effects on infertility is reversible. The circulating antibody titers correlated very well to the reduction in fertility. Furthermore, the anti-rmFA-1 antibodies from the immunized mice caused a significant block to murine sperm-zona pellucida binding in IVF of murine oocytes. Western blot analyses showed that, the anti-rmFA-1 antibodies specifically recognized the $47 \mathrm{kDa}$ protein band (dimeric form of cognate FA-1 antigen) in testes protein extract but not in the extracts of somatic tissues tested, namely kidney, liver, intestine, spleen, muscle, heart, lung, brain, and ovary [29]. In a separate experiment involving 18 immuno-infertile men resulting from the presence of auto antibodies on their spermatozoa, FA-1 antigen was found to have removed these antibodies from the spermatozoa. It reduced the sperm-bound antibodies that inhibited acrosome reaction thus allowed sperm to undergo successful acrosome reaction induced by calcium ionophore [30]. In conclusion, 
due to its tissue specificity, and effects of its recombinant proteins on fertilization, FA-1 is the most appropriate candidate for formulation in immunocontraception. Further more, the native FA-1 antigen itself removes anti-sperm auto antibodies from spermatozoa of infertile men and results in increased rates of acrosome reaction, FA-1 may find its applications in the treatment and diagnosis of male infertility. However, whether the recombinant and/or synthetic epitopes are used as single formulation, this antigen appears to provide a highly specific and effective anti-sperm vaccine for contraception. Studies involving nonhuman primates and clinical trials on this molecule are yet to be conducted.

\section{$\mathrm{PH}-20$}

$\mathrm{PH}-20$ is a guinea-pig sperm protein of 64 $\mathrm{kDa}$ and is anchored in the sperm membrane by a glycosyl phosphatidyl inositol (GPI) [31]. The cDNA encoding for the $\mathrm{PH}-20$ antigen has been cloned and sequenced from guinea-pig, cyanomologous monkey and human testis [32, 33]. The human sequence encodes 509 aa with 59\% identity to that of guinea-pig $\mathrm{PH}-20$. Southern blot analysis indicates that it is encoded by a 2.4 $\mathrm{kb}$ single gene mRNA transcript in the human genome. It is testis-specific by Northern blot and not present in other tissues (uterus, duodenum, ovary, spleen, and liver) tested. The cyanomologous monkey sequence encodes 510 aa with $90 \%$ and $94 \%$ homology to the human sequence at aa and DNA levels respectively. It only differs from the human sequence in having a glycine residue at position 53. $\mathrm{PH}-20$ is a bi-functional protein since it has both hyaluronidase activity and a separate zona-binding moiety [34]. Fully effective and reversible contraception was obtained in male and female guinea-pigs immunized with even low doses of the antigen $[35,36]$. In another study, to analyze the immunopathological effects of $\mathrm{PH}-20$ in the reproductive tract, male guinea pigs were immunized with $\mathrm{PH}-20$. It was found that, almost all $\mathrm{PH}-20$-immunized males became infertile, with remarkable loss spermatozoa or presence of abnormal spermatozoa in the cauda epididymides.
This complete loss of sperm in the epididymis resulted in infertility, but was however, accompanied with testes experimental autoimmune orchitis (EAO) [37]. Recently, using selected $\mathrm{PH}-20$ epitopes and different adjuvants, macaque monkeys had been immunized [38]. It was concluded that antigens derived from synthesized peptides and recombinant proteins representing selected regions of the $\mathrm{PH}-20$ molecule can be used as vaccine components in combination with the adjuvant Montanide to elicit a significant sperm-directed antibody response in immunized macaques. Shortened forms of recombinant $\mathrm{PH}$ 20 constructs were cloned to enhance expression of the protein in bacterial cells.

\section{Lactate dehydrogenase C4 (LDH-C4)}

The isozyme of lactate dehydrogenase ( $\mathrm{LDH})$ that is specific to testis, designated LDH-C4, is the predominant $\mathrm{LDH}$ isozyme in mammalian spermatozoa. It was developed from a highaffinity purified monoclonal antibody designated RG-4 to murine LDH-C4 [39]. It is an antigenic protein that occurs only in spermatozoa and the mature testis and the antibody-combining sites had been mapped [40]. Female mice immunized with high doses of LDH-C4, achieved $80 \%$ reversible infertility and this correlated with serum antibody levels. However, low dose of immunogen produced insignificant infertility [41]. In another study, it was found that hyperimmunization of male mice with human LDH-C4 evoked autoimmune reactions illustrated by the loss of LDH activity, associated histopathological changes in testis and epididymis and induction of sterility in mice [42]. Two female baboons, immunized with human LDH-C4, produced low antibody titers that were markedly enhanced by booster injections of murine LDH-C4. In this study, it was concluded that the contraceptive effect of the vaccine containing LDH-C4 was related to antibody titer and was reversible. Normal pregnancy ensued in animals in which the titer declined after termination of booster injections of vaccine [43]. Furthermore, female baboons were immunized with synthetic peptides (hC1-20), 
known to stimulate helper $T$-cell response, and other chimeric peptide (bC5-19:TT), a chimera between an LDH-C4 B-cell epitope and a 'promiscuous' T-cell epitope from tetanus toxin which has been shown to bind to and stimulate many different major histocompatibility complex alleles. Using this formulation, the peptides were found to be immunogenic in these animals (baboons) as well as in rabbits and that the chimera elicited consistently high antibody titers and immunogenicity in all the 19 wild caught baboons that were immunized. The mating experiments further showed that $62 \%$ of the baboons immunized with the chimera had reduced fertility [44]. On a separate stuciy, using similar approach, female cyanomologous macaques were immunized with same peptide sequence (bC5-19) conjugated to a T-cell epitope from tetanus toxin (TT). It was found that all 12 females in the treatment group developed LDH-C4-specific serum antibodies, but anti-LDH-C4 antibodies were not detected in vaginal fluids of the immunized animals. After 4 months of timed mating immediately following the immunizations, five of the ten immunized females became pregnant, as did six of the ten control females. Antisera from both pregnant and non-pregnant bC5-19:TT-immunized females recognized a single band at $35 \mathrm{kDa}$ on western blots of whole sperm extracts, and purified immunoglobulins from the same sera localized along the principle piece of the flagellum of permeabilized sperm [45]. Recently, four sexually mature male baboons (Papio sp.) were immunized with a chimeric peptide containing a B-cell epitope of the LDH-C4 and a promiscuous T-cell epitope of tetanus toxin. The study demonstrated that this epitope of LDHC4 did not cause autoimmune disease and that sperm from these immunized males had a diminished zona binding capacity, suggesting that a safe male immunocontraceptive based on development of anti-sperm anti-bodies may be feasible [46].

\section{Animal Models for Immunocontraceptive Research}

Most of candidate sperm immunocontraceptive molecules have been identified and / or characterized in mice, rats, hamsters, guinea-pigs and rabbits. Due to their small size, these animals are easy to manipulate and inexpensive especially when large numbers are required for experiments. However, the findings from these experimental systems (involving small animals) may not necessarily be representative of that in man. Man is the ultimate beneficiary of an immunocontraceptive vaccine(s) although other animals (veterinary, wild and domestic), may also benefit. Use of human subjects for experimentation is however, restricted for ethical and legal implications. It is clear that once these molecules are characterized in the small animals, they have to be tested on non-human primates before undergoing human clinical trials. The nonhuman primate animal therefore plays a central role in contraceptive vaccine development and the animal of choice should not be very large like the chimpanzees, but medium sized and cheaper. Baboons and macaque monkeys are the likely candidates in this regard. However, very little reproductive biology data exists that interlinks the vaccine candidates, non-human primates and the humans. Information on hormonal profiles, spermiogram, immune response, and gene homologies may be valuable. Except for LDH-C4, $\mathrm{Sp}-10$ and $\mathrm{Sp}-17$ immunocontraceptive vaccine candidates, none of the other molecules have comparative data on these mammalian species and human. The baboon (Papio sp) seems to be an attractive candidate. First it is an old world primate and larger colonies exist in Africa (Kenya), where it is regarded as a pest (large colonies of these animals invade crops and human settlements), hence it is easily available and cheaper. Second, data exists to the effect that the spermatogenesis in baboon is intermediate to that of human and rodents [47]. The hormonal profiles of female baboons are very similar to that of humans. Third monoclonal antibodies against 
baboon sperm have been found to cross-react with antigens on human spermatozoa [48]. Finally, molecular biology techniques used in characterization of sperm or testes antigens for use as immunogen, have demonstrated significant homologies of the DNA sequences between the baboon and humans. In LDH-C4 studies, the baboon gene was found to have $99.3 \%$ identity in amino acid sequences to that of human, indicating that this molecule would be an effective antigen in nonhuman primates [49]. The baboon $\mathrm{Sp}-17$ protein sequence is $97 \%$ identical to human Sp-17 but differs significantly by the addition of 12 amino acids at the $\mathrm{C}$-terminal, providing an additional potential protein kinase $\mathrm{C}$ phosphorylation site. However bSp-17 has $74 \%$ and $77 \%$ homologies to that of the mouse and rabbit Sp-17 DNA sequences respectively [21]. Sp-10 is the most extensively studied molecule in terms of its gene homologies. Where as the baboon $\mathrm{Sp}-10$ is $60 \%$ homologous to the mouse sequence and $85 \%$ homologous to the human [13], there is $98 \%$ homology between baboon and macaque $\mathrm{Sp}-10$ at the protein and DNA levels. There is also an $85 \%$ and $89 \%$ homology between baboon and macaque Sp-10 and human Sp-10 at the protein and DNA levels, respectively. However, a mouse intra-acrosomal protein, MSA-63, considered to be an $\mathrm{Sp}-10$ homologue, exhibited an overall $53 \%$ homology to non-human primate $\mathrm{Sp}-10$ and a $60 \%$ homology to human $\mathrm{Sp}-10$ at the protein level. Fox, $\mathrm{Sp}-10$ gene designated cFSA-Acr.1, is found to be highly homologues to that of the human within the carboxyl terminal. However, the fox sequence shows unique sequences absent from both the human, baboon Sp-10, and mouse MSA63 sequences [9]. It is clear from these studies that a database that interlinks characteristic of these molecules in non-human primates and human is necessary. This should be developed alongside other characterization studies on these molecules.

\section{Discussion and Conclusion}

Spermatogenesis and fertilization are two very well understood processes that are prime targets for the development of a sperm specific immunocontraceptive molecule. Unique events in the testicular spermiogenesis, epididymal maturation, and the oviductal sperm capacitation and acrosome reaction are some of the important points for intervention.

A variety of these molecular targets have been identified, most extensively characterized include LDH-C4, FA-1, Sp-17, Sp-10, PH-20. The molecule to be used as an immunogen must be immunogenic, specific, and effective and must have no immunopathological effects.

\section{Cytotoxicity and Immunogenicity}

In guinea-pigs, the fully effective and reversible contraception that was obtained as a result of $\mathrm{PH}-20$ immunization was accompanied by a testicular immunopathological effect, the experimental autoimmune orchitis (EAO) [37]. This problem has been addressed by B-cell epitope analysis, and use of alternative adjuvants such as Montanide. Although significant antibody levels were obtained in immunized macaques, it is still unclear whether the problem of EAO has been solved or not. In conclusion, due to its location on the sperm surface and its multiple functionality, during fertilization, the $\mathrm{PH}-20$ protein represents a very promising candidate for contraceptive vaccine development if only its immunopathological effects can be eradicated. LDH-C4 on the other hand is a poor immunogen in addition to inducing EAO. Immunogenicity problems appeared to have been resolved by a combined use of specific chimeric peptide and TT adjuvant immunization in baboons [44]. The results from the baboon study have however been recently disputed by the macaque study [45].

\section{Specificity}

$\mathrm{Sp}-17$ has been associated with problems of specificity. The complete nucleotide and deduced amino acid sequences of human $\mathrm{Sp}-17$ transcripts 
are reported and it is shown that they are expressed in a wide range of tissues, albeit at a much lower expression than in the testis [24]. Although Sp-17 expression is highest in the testis, it is present in the entire mouse somatic tissues examined and is highly conserved throughout all mammalian species [25]. Thus it is present in other somatic tissue and not restricted to the testes as earlier claimed. Other reports indicating Sp-17 as a novel cancer-testis (CT) antigen in multiple myeloma (MM), suggesting that it may be an excellent target for tumor vaccine of MM [26]. These problems would have been circumvented by hybridization studies including in-situ, northern and southern blotting experiments. If these are done earlier at the on set of the molecular characterizations, all of effort and resources could be saved. However, for $\mathrm{Sp}-17$, these latter findings associate it with other functions other than zona binding.

In conclusion, the road towards the development of a sperm specific immunocontraceptive vaccine is very promising although tortuous. It is known that in mammals, the testicular sperm is infertile, and the spermatozoon acquires its fertilizing attribute as it traverses its way through the epididymis. The epididymus is thus clear target and must be vigorously investigated.

\section{References}

1) United Nations Population Division. 1984. World population prospects; In: Estimates and projections as assessed in 1982, to be issued as a United National Publication; data reproduced in the review of appraisal of the world population, plan of action; Report of the Secretary General, United Nations International Conference on Population, Mexico City, August; E/conf.76/4/corr.1-26 July, 1984. pp 29-30.

2) Tuckwell HC and Koziol J A. 1992. World population. Nature 359: 200.

3) United Nations. 1989. Levels and trends of contraceptive use as assessed in 1988. New
York 1989. Population Studies No. 110.

4) Aitken RJ. 2002. Immunocontraceptive vaccines for human use. J. Reprod. Immunol. 57: 273-287.

5) Frayne $\mathrm{J}$ and Hall L. 1999. The potential use of sperm antigens as targets for immunocontraception; past, present and future. J. Reprod. Immun. 43: 1-33.

6) Bedford JM. 1966. Development of the fertilizing ability of spermatozoa in the epididymis of rabbit. J. Exp. Zool, 164: 319-329.

7) Diekman $A B$, Norton EJ, Westbrook VA, Klotz $\mathrm{KL}$, Naaby-Hansen $S$ and Herr JC. 2000. Anti-sperm antibodies from infertile patients and their cognate sperm antigens: a review. Identity between SAGA-1, the H6-3C4 antigen, and CD52. Am. J. Reprod. Immunol. 43: 134-143.

8) Baskin MJ. 1932. Temporary sterilization by the injection of human spermatozoa. A preliminary report. Am. J. Obstet. Gynec. 24: 892-897.

9) Beaton S, ten Have J, Cleary A and Bradley MP. 1995. Cloning and partial characterization of the cDNA encoding the fox sperm protein FSA-Acr.1 with similarities to the Sp-10 antigen. Mol. Reprod. Dev. 40: 242-252.

10) Coonrod SA, Herr JC and Westhusin ME. 1996. Inhibition of bovine fertilization in vitro by antibodies to $\mathrm{Sp}-10$. J. Reprod. Fertil 107: 287-297.

11) Freemerman $A J$, Wright RM, Flickinger $C J$ and Herr JC. 1994. Tissue specificity of the acrosomal protein Sp-10: a contraceptive vaccine candidate molecule. Biol. Reprod. 50: 615-621.

12) Reddi PP, Castillo JR, Klotz K, Flickinger CJ and Herr JC. 1994. Production in Escherichia coli, purification and immunogenicity of acrosomal protein $\mathrm{Sp}-10$, a candidate contraceptive vaccine. Gene. 147:189-195.

13) Freemerman AJ, Wright RM, Flickinger CJ and Herr JC. 1993. Cloning and sequencing of baboon and cynomolgus monkey intraacrosomal protein Sp-10: homology with human SP-10 and a mouse sperm antigen 
(MSA-63). Mol. Reprod. Dev. 34: 140-148.

14) Kurth $B E$, Weston $C$, Reddi PP, Bryant $D$, Bhattacharya R, Flickinger $\mathrm{CJ}$ and Herr JC. 1997. Oviductal antibody response to a defined recombinant sperm antigen in macaques. Biol. Reprod. 57: 981-989.

15) Hamatani $T$, Tanabe $K$, Kamei $K$, Sakai $N$, Yamamoto $Y$ and Yoshimura $Y$. 2000. A monoclonal antibody to human Sp-10 inhibits in vitro the binding of human sperm to hamster oolemma but not to human Zona pellucida. Biol. Reprod. 62: 1201-1208.

16) O'Rand MG. 1981. Inhibition of fertility and sperm-zona binding by antiserum to the rabbit sperm auto antigen. Biol. Reprod. 25: 621628.

17) O'Rand MG, Irons GP and Porter JP. 1984. Monoclonal antibodies to rabbit sperm autoantigen I. Inhibition of in vitro fertilisation and localization on the egg. Biol. Reprod. 30: 721-729.

18) Kong $M$, Richardson $R T$, Widgren $E E$ and O'Rand MG. 1995 Sequence and localization of the mouse sperm auto antigenic protein, Sp-17. Biol. Reprod. 53: 579-590.

19) Richardson RT, Yamasaki $N$ and O'Rand MG 1994. Sequence of a rabbit sperm zona pellucida binding protein and localization during the acrosome reaction. Dev. Biol. 165: 688-701.

20) Lea I A, Richardson RT, Widgren $E E$ and O'Rand MG. 1996. Cloning and sequencing of cDNAs encoding the human sperm protein, Sp17. Biochim. Biophys. Acta. 1307: 263266.

21) Adoyo PA, Lea IA, Richardson RT, Widgren EE and O'Rand MG. 1997. Sequence and characterization of the sperm protein Sp-17 from the baboon. Mol. Reprod. Dev. 47: 6671.

22) Lea I A, Kurth B and O'Rand MG. 1998a. Immune response to immunization with sperm antigens in the macaque oviduct. Biol. Reprod. 58: 794-800.

23) Lea I A, van Lierop MJ, Widgren EE, Grootenhuis $A$, Wen $Y$, van Duin $M$ and
O'Rand MG. 1998b. A chimeric sperm peptide induces antibodies and strain-specific reversible infertility in mice. Biol. Reprod. 59: 527536.

24) Frayne $J$ and Hall L. 2002. A re-evaluation of sperm protein $17(\mathrm{Sp}-17)$ indicates a regulatory role in an A-kinase anchoring protein complex, rather than a unique role in sperm-zona pellucida binding. Reproduction. 124: 767-774.

25) Wen $Y$, Richardson RT, Widgren $E E$ and O'Rand MG. 2001. Characterization of Sp-17: a ubiquitous three-domain protein that binds heparin. Biochem. J. 357: 25-31.

26) Chiriva-Internati $M$, Wang $Z$, Salati $E$, Bumm K, Barlogie B and Lim SH. 2002. Sperm protein $17(\mathrm{Sp}-17)$ is a suitable target for immunotherapy of multiple myeloma. Blood. 100: 961-965.

27) Zhu $X$ and Naz RK. 1997. Fertilization antigen-1: cDNA cloning, testis-specific expression, and immunocontraceptive effects. Proc. Natl. Acad. Sci. U S A. 94: 4704-4709.

28) Naz RK and Zhu X. 2002. Molecular cloning and sequencing of CDNA encoding for human FA-1 antigen. Mol. Reprod. Dev. 63: 256268.

29) Naz RK and Zhu X. 1998. Recombinant fertilization antigen-1 causes a contraceptive effect in actively immunized mice. Biol. Reprod. 59: 1095-1100.

30) Menge AC, Christman GM, OhI DA and Naz RK. 1999. Fertilization antigen-1 removes antisperm autoantibodies from spermatozoa of infertile men and results in increased rates of acrosome reaction. Fertil. Steril. 71: 256260.

31) Hunnicutt GR, Mahan K, Lathrop WF, Ramarao CS, Myles DG and Primakoff P. 1996. Structural relationship of sperm soluble hyaluronidase to the sperm membrane protein $\mathrm{PH}-20$. Biol. Reprod. 54: 1343-1349.

32) Lathrop WF, Carmichael EP, Myles DG and Primakoff P. 1990. cDNA cloning reveals the molecular structure of a sperm surface protein, $\mathrm{PH}-20$, involved in sperm-egg adhesion and 
the wide distribution of its gene among mammals. J. Cell Biol. 111: 2939-2949.

33) Lin $Y$, Kimmel LH, Myles DG and Primakoff $P$. 1993. Molecular cloning of the human and monkey sperm surface protein $\mathrm{PH}-20$. Proc. Natl. Acad. Sci. USA 90: 10071-10075.

34) Hunnicutt GR, Primakoff $P$ and Myles DG. 1996. Sperm surface protein $\mathrm{PH}-20$ is bifunctional: one activity is a hyaluronidase and a second, distinct activity is required in secondary sperm-zona binding. Biol. Reprod. 55: 80-86.

35) Primakoff $P$, Cowan $A$, Hyatt $H$, Tredick-Kline $J$ and Myles DG. 1988. Purification of the guinea pig sperm $\mathrm{PH}-20$ antigen and detection of a site-specific endoproteolytic activity in sperm preparations that cleaves $\mathrm{PH}-20$ into two disulfide-linked fragments. Biol. Reprod. 38: 921-934.

36) Primakoff $P$, Woolman-Gamer L, Tung K S and Myles DG. 1997. Reversible contraceptive effect of $\mathrm{PH}-20$ immunization in male guinea pigs. Biol. Reprod. 56: 1142-1146.

37) Tung KS, Primakoff $P$, Woolman-Gamer $L$ and Myles DG 1997. Mechanism of infertility in male guinea pigs immunized with sperm $\mathrm{PH}$ 20. Biol. Reprod. 56: 1133-1141.

38) Deng $X$, Meyers SA, Tollner TL, Yudin Al, Primakoff PD, He DN and Overstreet JW. 2002. Immunological response of female macaques to the $\mathrm{PH}-20$ sperm protein following injection of recombinant proteins or synthesized peptides. J. Reprod. Immunol. 54: 93-115.

39) Goldman-Leikin RE and Goldberg E. 1983. Characterization of monoclonal antibodies to the sperm-specific lactate dehydrogenase isozyme. Proc. Natl. Acad. Sci. U S A. 80: 3774-3778.

40) Wheat TE and Goldberg E. 1985. Antigenic domains of the sperm-specific lactate dehydrogenase $\mathrm{C} 4$ isozyme. Mol. Immunol. 22: 643-649.

41) Gupta GS, Malhotra R and Sehgal S. 1994.
Regulation of fertility in female mice after immunization with human sperm specific LDH: role in conception and contraception. Indian J Exp Biol. 32: 14-19.

42) Gupta GS and Malhotra R. 1994. Autoimmune-like activity of sperm specific LDH: a pathophysiological and electron microscopic study of atrophied testis and epididymis. Indian J Biochem Biophys. 31: 480-485.

43) Goldberg E, Wheat TE, Powell JE and Stevens VC. 1981. Reduction of fertility in female baboons immunized with lactate dehydrogenase C4. Fertil. Steril. 35: 214-217.

44) O'Hern PA, Liang ZG, Bambra CS and Goldberg E. 1997. Co-linear synthesis of an antigen-specific B-cell epitope with a 'promiscuous' tetanus toxin T-cell epitope: a synthetic peptide immunocontraceptive. Vaccine. 15: 1761-1766.

45) Tollner TL, Overstreet JW, Branciforte $D$ and Primakoff PD. 2002. Immunization of female cynomolgus macaques with a synthetic epitope of sperm-specific lactate dehydrogenase results in high antibody titers but does not reduce fertility. Mol. Reprod. Dev. 62: 257264.

46) Goldberg E, VandeBerg JL, Mahony MC and Doncel GF. 2001. Immune response of male baboons to testis-specific LDH-C (4). Contraception. 64: 93-98.

47) Chowdhry, AK and Steinberger E. 1976. A study of germ cell morphology and duration of spermatogenic cycle in the baboon (Papio anubis). Anat. Rec. 185: 115-170.

48) Isahakia MA and Bambra CS. 1992. Antisperm and anti-ovum vaccines: the selection of candidate antigens and the outcome of preclinical studies. Scand. J. Immunol. Suppl. 11: 118-122.

49) O'Hern PA, Bambra CS, Isahakia $M$ and Goldberg E. 1995. Reversible contraception in female baboons immunized with a synthetic epitope of sperm-specific lactate dehydrogenase. Biol. Reprod. 52: 331-339. 